Article

\title{
Influence of Temperature on Mechanical Properties of P(BAMO-r-THF) Elastomer
}

\author{
Jinxian Zhai ${ }^{1, *}$, Hanpeng Zhao ${ }^{2}$, Xiaoyan Guo ${ }^{1}$, Xiaodong $\mathrm{Li}^{1}$ and Tinglu Song ${ }^{3}$ \\ 1 School of Materials, Beijing Institute of Technology, Beijing 100081, China; gxy@bit.edu.cn (X.G.); \\ bitlxd@bit.edu.cn (X.L.) \\ 2 China Academy of Railway Sciences, Standards and Metrology Research Institute, Beijing 100081, China; \\ crcczhaohp@126.com \\ 3 Experimental center of advanced materials, School of Materials, Beijing Institute of Technology, \\ Beijing 100081, China; song@bit.edu.cn \\ * Correspondence: zhjx@bit.edu.cn
}

Received: 28 September 2020; Accepted: 23 October 2020; Published: 28 October 2020

\begin{abstract}
The relationship between temperature and the mechanical properties of an end cross-linked equal molar random copolyether elastomer of 3,3-bis(azidomethyl)oxetane and tetrahydrofuran (P(BAMO-r-THF)) was investigated. During this investigation, the performances of two P(BAMO-r-THF) elastomers with different thermal histories were compared at different temperatures. The elastomer as prepared at $20{ }^{\circ} \mathrm{C}$ (denoted as S0) exhibited semi-crystallization morphology. Wide angle $\mathrm{X}$-ray diffraction analysis indicated that the crystal grains within elastomer S0 result from the crystallization of BAMO micro-blocks embedded in P(BAMO-r-THF) polymeric chains, and the crystallinity is temperature irreversible under static conditions. After undergoing a heating-cooling cycle, this elastomer became an amorphous elastomer (denoted as S1). Regarding mechanical properties, at $20^{\circ} \mathrm{C}$, break strains and stresses of $315 \pm 22 \%$ and $0.46 \pm 0.01 \mathrm{MPa}$ were obtained for elastomer S0; corresponding values of $294 \pm 6 \%$ and $0.32 \pm 0.02 \mathrm{MPa}$ were obtained for elastomer S1. At $-40{ }^{\circ} \mathrm{C}$, these strains and stresses simultaneously increased to $1085 \pm 21 \%$ and $8.90 \pm 0.72 \mathrm{MPa}(\mathrm{S} 0)$ and $1181 \pm 25 \%$ and $10.23 \pm 0.44 \mathrm{MPa}(\mathrm{S} 1)$, respectively, owing to the strain-induced crystallization of BAMO micro-blocks within the P(BAMO-r-THF) polymeric chains.
\end{abstract}

Keywords: P(BAMO-r-THF) elastomer; BAMO micro-block; aggregation morphology; mechanical properties; strain-induced crystallization

\section{Introduction}

Solid rocket propellants are a type of composites composed of (among others) polymeric binders, curing agents, high-energy additives, oxidizers, metallic fuel additives, and burning rate modifiers. The binders are generally used to bind together other ingredients to form a tough elastomeric three-dimensional structure [1]. Polymeric binders with excellent mechanical properties can effectively absorb, dissipate exterior applied load, and maintain propellant structural integrity under various intricate conditions. Compared with traditional hydroxyl-terminated polybutadiene inert binders, energetic binders can enhance the energy level as well as increase the burning rate and specific impulse of propellant systems. That is, these binders release additional heat and lead to an increase in the temperature of pyrolysis and combustion, and hence, have attracted considerable attention [2].

Energetic azido polymeric binders, such as glycidyl azido polymer (GAP), poly[(3-azidomethyl)methyloxetane] (PAMMO), and poly(3,3-bis(azidomethyl)oxetane) (PBAMO), have been extensively investigated because azido bond decomposition is associated with the evolution of a large amount of energy $\left(355 \mathrm{~kJ} \mathrm{~mol}^{-1}\right)$ [3-5]. In fact, PBAMO is quite attractive, owing to the high 
energy arising from the two $-\mathrm{N}_{3}$ bonds in the monomer structure. Unfortunately, due to the symmetry of the BAMO monomer and the stereo-regularity of the BAMO homo-polymeric chain, PBAMO is prone to crystallization, exhibits a relatively high glass transition temperature $\left(\mathrm{T}_{\mathrm{g}}\right)$, and is solid at room temperature. This results in inadequate mechanical properties (break strain: $\sim 10 \%$ ), thereby severely limiting the practicality of PBAMO [6-8].

Randomly introducing a second monomer into a homo-polymerization chain structure, constructing irregular segment structures, and increasing the configuration entropy represent an effective approach of inhibiting polymer crystallinity [9]. The copolymerization of BAMO with other cyclic ether monomers by means of cationic ring opening polymerization is a simple and effective method of improving the practicality of PBAMO. Petrov et al. found that the crystallinity of BAMO/AMMO random copolyethers (P(BAMO-r-AMMO)) decreases gradually with increasing AMMO content. When AMMO and BAMO monomers are equimolar and are homogeneously distributed within $\mathrm{P}(\mathrm{BAMO}-\mathrm{r}-\mathrm{AMMO})$ polymeric chains, the crystallinity of BAMO micro-blocks can be effectively restrained [10]. However, the bulky side group of AMMO monomer is disadvantageous to decreasing the polymer glass transition temperature [11], and hence, the $T_{g}$ of the resulting $\mathrm{P}(\mathrm{BAMO}-\mathrm{r}-\mathrm{AMMO})$ is approximately $-35{ }^{\circ} \mathrm{C}$ [12]. Similarly, owing to the bulky side groups of 3-nitratomethyl-3-methyloxetane (NMMO), a BAMO/NMMO random copolymer is characterized by a $\mathrm{T}_{\mathrm{g}}$ of $-23^{\circ} \mathrm{C}$. These are unfavorable to the mechanical properties, especially at low temperature [13].

Poly(tetrahydrofuran) (PTHF) is composed of a flexible chain structure and is often used to tailor the low-temperature mechanical properties of crystalline polymers [14,15]. The equal molar random copolyether of BAMO with THF (P(BAMO-r-THF), see Scheme 1) exists as a liquid at room temperature and is characterized by a $\mathrm{T}_{\mathrm{g}}$ of approximately $-60^{\circ} \mathrm{C}$, simultaneously meeting energy and mechanical-property requirements [16]. Correspondingly, some applied studies, such as $\mathrm{P}(\mathrm{BAMO}-\mathrm{r}-\mathrm{THF})$ propellant thermal decomposition, combustion, and performance modification, have been intensively reported [17-19]. However, to date, few studies on the mechanical behaviors of $\mathrm{P}$ (BAMO-r-THF) binders have been reported.

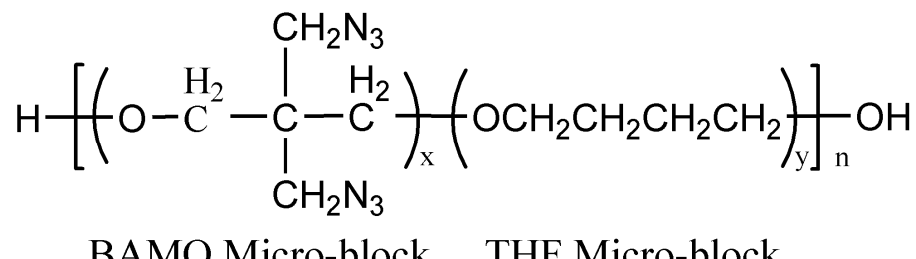

BAMO Micro-block THF Micro-block

Scheme 1. Molecular structure of prepolymer P(BAMO-r-THF).

Exploring the mechanical behaviors of P(BAMO-r-THF) binders is essential to the use of these binders in practical applications. In a propellant system, a P(BAMO-r-THF) binder is end-reacted with a multifunctional curing agent, forming a three-dimensional crosslinking network and bearing applied loads [1]. In the present study, a hydroxyl terminated equal molar random copolyether of P(BAMO-r-THF) and polyisocyanate N100 (hexamethylene diisocyanate- $\mathrm{H}_{2} \mathrm{O}$ adduct) were used as a binder and a cross-linker, respectively [20]. These components were used to prepare urethane end-crosslinked P(BAMO-r-THF) elastomers based on the reaction between terminal hydroxyl and isocyanate. The relationship between temperature and the mechanical behaviors of the elastomers was systematically investigated.

\section{Experimental}

\subsection{Materials}

A hydroxyl terminated equal molar random copolyether of 3,3-bis(azidomethyl) oxetane with tetrahydrofuran (P(BAMO-r-THF), hydroxyl value: $0.36 \mathrm{mmol} \mathrm{g}^{-1}$, number average molecular weight: $5600 \mathrm{~g} \mathrm{~mol}^{-1}$, polydispersity index: 1.72 ) and $\mathrm{N} 100$ (isocyanate concentration: $5.25 \mathrm{mmol} \mathrm{g}^{-1}$, 
functionality: 3.9), were provided by Liming Research Institute of Chemical Industry (Luoyang, China) and used as an energetic binder and a polyisocyanate cross-linker, respectively. Furthermore, dibutyltin dilaurate (Alfa Aesar, Tianjin, China) were purchased and used as a curing catalyst.

\subsection{Elastomer Preparation}

Utilizing an equivalent molar ratio of isocyanate comprising N100 to hydroxyl comprising prepolymer $\mathrm{P}(\mathrm{BAMO}-\mathrm{r}-\mathrm{THF})$, all components were uniformly mixed according to the composition listed in Table 1, and degassed under vacuum. The mixture was cured at $20^{\circ} \mathrm{C}$ until the isocyanate groups disappeared completely, as indicated by Fourier transform infrared spectroscopy. The resultant elastomer was kept at $20^{\circ} \mathrm{C}$ and was denoted as S0. To eliminate the kinetic influence of changes in elastomer aggregation, the partial elastomer (S0) was heated to $50{ }^{\circ} \mathrm{C}$ and held for $30 \mathrm{~min}$. Afterward, the elastomer was held at $20^{\circ} \mathrm{C}$, and the resulting elastomer was denoted as $\mathrm{S} 1$.

Table 1. Composition (mass ratio) of P(BAMO-r-THF) elastomer.

\begin{tabular}{ccc}
\hline P(BAMO-r-THF) & N100 & Dibutyltin Dilaurate \\
\hline 100 & 6.86 & 0.13 \\
\hline
\end{tabular}

\subsection{Characterization}

Non-isothermal differential scanning calorimetry (DSC) was used to characterize the temperature thermal-response of end-crosslinked P(BAMO-r-THF) elastomers on an F204 instrument (Netzsch, Bavaria, Germany) equipped with a refrigerated cooling system. Temperature calibration was performed using an indium standard $\left(\mathrm{T}_{\mathrm{m}}=156.6^{\circ} \mathrm{C}\right)$. Using liquid nitrogen, elastomer samples weighing $10 \mathrm{mg}$ were quenched to from $20^{\circ} \mathrm{C}$ to $-100{ }^{\circ} \mathrm{C}$. Afterward, DSC tests were performed at a heating rate of $2 \mathrm{~K} \mathrm{~min}^{-1}$ under a nitrogen atmosphere.

The morphology of $\mathrm{P}$ (BAMO-r-THF) elastomers was observed via polarizing optical microscopy (POM; Olympus BX51, Olympus Corporation, Tokyo, Japan). The microscope was equipped with a computer-controlled CCD camera and a thermal platform (THMS600, Linkam, Tadworth, UK). The P(BAMO-r-THF) elastomer films (thickness: $50 \mu \mathrm{m}$ ) were sandwiched between two clean glass slides and then quenched from $20^{\circ} \mathrm{C}$ to $-50^{\circ} \mathrm{C}$. The specimens were kept at the designated temperatures for $30 \mathrm{~min}$, and then POM micrographs were captured at temperatures ranging from low to high.

Wide-angle X-ray diffraction (WAXD) measurements of P(BAMO-r-THF) elastomers were conducted on an automatic powder diffractometer (D8 Advance, Bruker-AXS, Karlsruhe, Germany; $\mathrm{Ni}$-filtered $\mathrm{Cu} \mathrm{K} \alpha$ radiation $(40 \mathrm{kV}, 40 \mathrm{~mA})$ ) equipped with a thermal platform. WAXD profiles were obtained in a $2 \theta$ scan mode for $2 \theta$ ranging from $5^{\circ}$ to $40^{\circ}$. Prior to these measurements, the elastomer samples were quenched from 20 to $-50^{\circ} \mathrm{C}$. From low to high temperature, the specimens (dimensions: $13 \times 8 \times 1 \mathrm{~mm}^{3}$ ) were held for $30 \mathrm{~min}$ at the selected temperature, and the WAXD measurements were performed at a scanning rate of $5^{\circ} \mathrm{min}^{-1}$.

We obtained load-extension curves of P(BAMO-r-THF) elastomers through uniaxial stretching on a mechanical tester (Instron 6022, Instron Corporation, Eden Prairie, MN, USA). Elastomer specimens were cut to a dumbbell shape (dimensions: $100 \times 20 \times 5 \mathrm{~mm}^{3}$ ). Subsequently, the specimens were fixed in the mechanical tester, and kept at the designated drawing temperature for $30 \mathrm{~min}$, allowing temperature equilibration prior to the drawing process. The mechanical tests were conducted at a constant cross-head strain rate of $20 \mathrm{~mm} \cdot \mathrm{min}^{-1}$.

\section{Results and Discussion}

\subsection{Thermal Properties}

The non-isothermal differential scanning calorimetric (DSC) curves of P(BAMO-r-THF) elastomers $\mathrm{S} 0$ and $\mathrm{S} 1$ are shown in Figure 1. In each case, a step peak occurs at approximately $-50{ }^{\circ} \mathrm{C}$, corresponding 
to the glass transition temperature of each elastomer [21]. For temperatures ranging from 25 to $38^{\circ} \mathrm{C}$, elastomer S0 gives rise to a sharp endothermic peak, whereas elastomer S1 gives rise to a straight line, without a perceptible thermal effect. This indicates that after elastomer $\mathrm{S} 0$ undergoes a heating-cooling treatment, the resulting elastomer (i.e., S1) exhibits completely different thermal behavior.

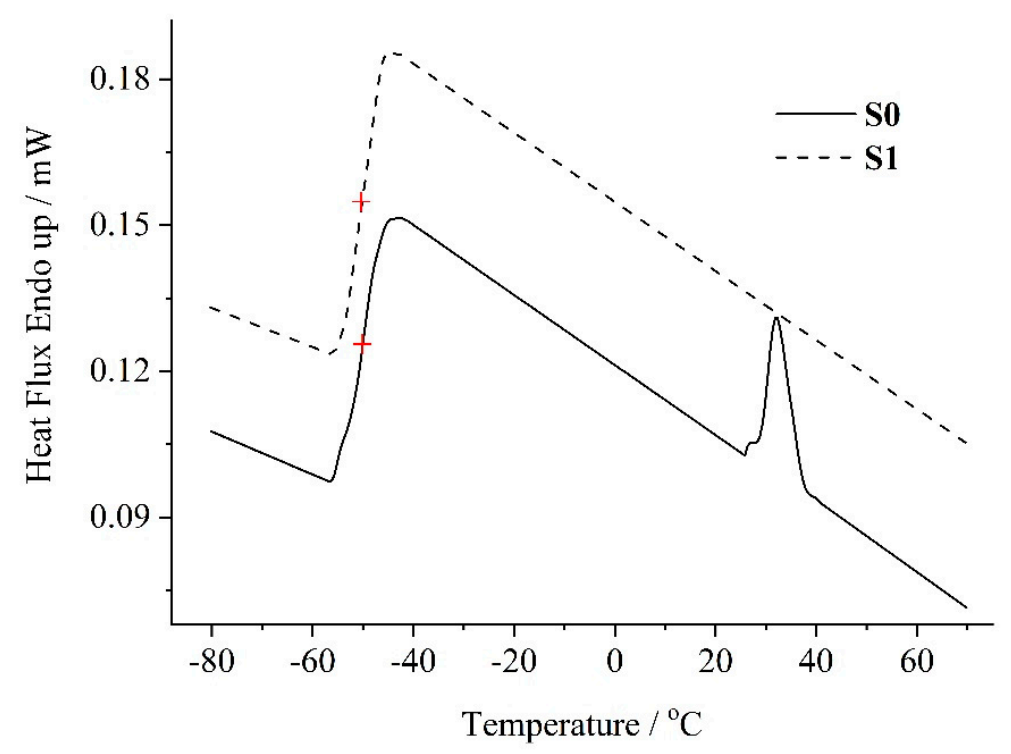

Figure 1. Differential scanning calorimetry (DSC) curves of P(BAMO-r-THF) elastomers.

\subsection{Aggregation Morphologies}

Through polarizing optical microscopy (POM), the aggregation morphologies associated with different thermal histories of P(BAMO-r-THF) elastomers S0 and S1 are continuously observed for temperatures ranging from low to high. The $\mathrm{POM}$ snapshots of elastomer $\mathrm{S} 0$ at different temperatures (see Figure 2) reveal that, at temperatures below $40{ }^{\circ} \mathrm{C}$, many small bright patches occur in the elastomer. This indicates that, in the elastomer matrix, some polymeric segments are orderly arrayed in a micro-domain and form small crystal grains below $40^{\circ} \mathrm{C}$. Moreover, these grains are very sensitive to temperatures lying between 25 and $40^{\circ} \mathrm{C}$, and gradually decrease in size with increasing temperature. When heated to $40{ }^{\circ} \mathrm{C}$, the bright patches disappear completely. This indicates that elastomer S0 prepared at $20^{\circ} \mathrm{C}$ is a semi-crystalline morphology elastomer below $40{ }^{\circ} \mathrm{C}$, and an amorphous morphology elastomer above $40^{\circ} \mathrm{C}$. 


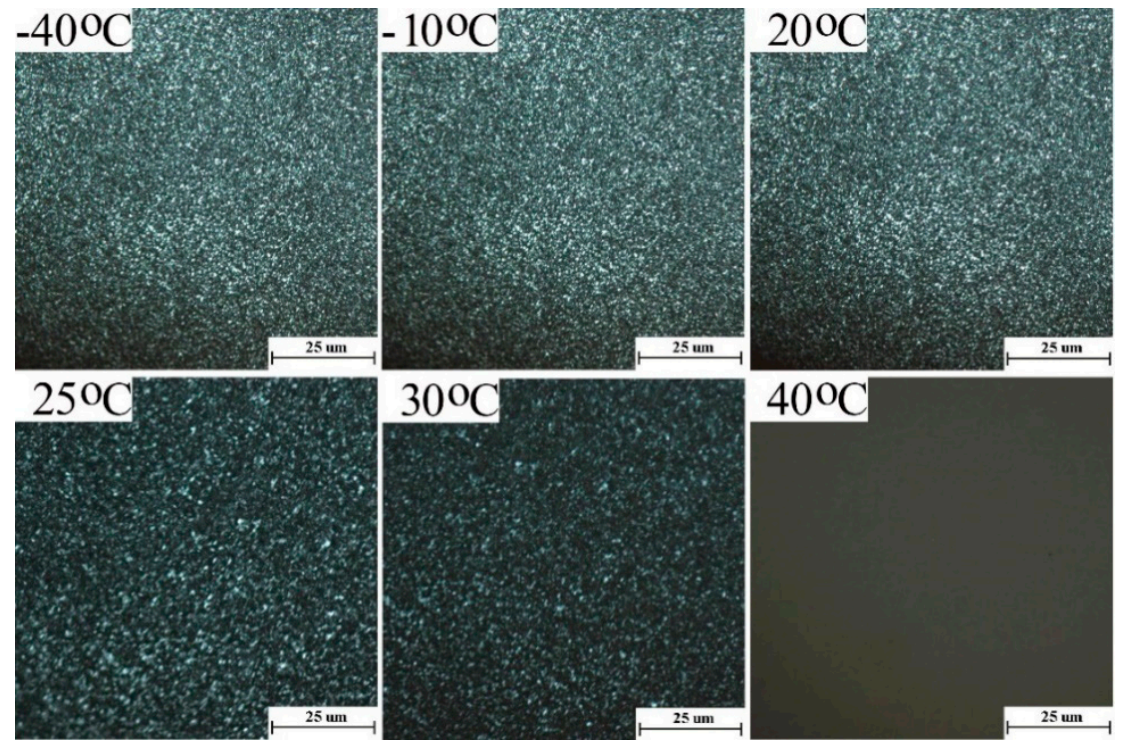

Figure 2. Polarizing optical microscopy (POM) snapshots of elastomer S0 at different temperatures.

In contrast to the trend observed for elastomer $\mathrm{S}$, no bright patches are observed for elastomer $\mathrm{S} 1$ at temperatures ranging from -40 and $40{ }^{\circ} \mathrm{C}$ (see Figure 3). This indicates that elastomer S1 is characterized by an amorphous aggregation state for the temperatures considered. Taken together with the DSC curves of the elastomers (see Figure 1), these results indicate that the endothermic peak of S0 for temperatures ranging from 25 to $38^{\circ} \mathrm{C}$ results from the melting of crystal grains. Moreover, semi-crystalline elastomer S0 transforms into amorphous elastomer S1 after heating, and simply reducing the temperature yields no recovery of the semi-crystalline structure.

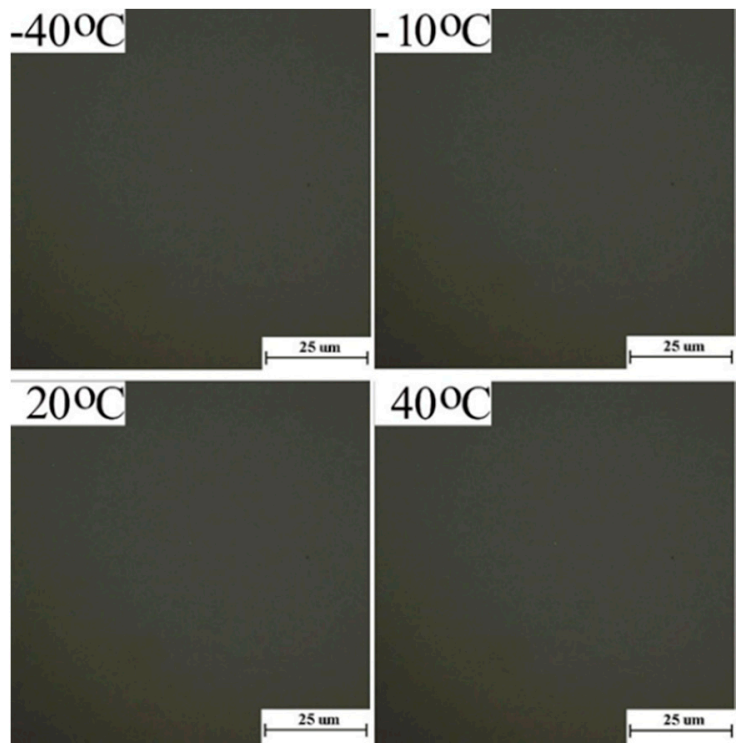

Figure 3. POM snapshots of elastomer S1 at different temperatures.

\subsection{Wide-Angle X-ray Diffraction}

The crystal grain composition of elastomer S0 is determined via wide-angle X-ray diffraction (WAXD), where WAXD profiles are obtained at different temperatures (see, Figure 4 (Left)). For elastomer S0 at temperatures ranging from -40 to $20{ }^{\circ} \mathrm{C}$, sharp diffraction peaks emerge at $16.8^{\circ}$ and $24.1^{\circ}$, corresponding to the characteristic diffraction peaks of PBAMO crystallization [22]. Because BAMO random copolymerization with other monomers merely restrains (rather than 
eliminates) the crystallization of BAMO homo-polymerization segments $[10,23,24]$, in combination with P(BAMO-r-THF) polymer chain structure (see Scheme 1), the small crystal grains within elastomer S0 are generated by the crystallization of BAMO micro-blocks embedded in the P(BAMO-r-THF) prepolymer. These crystalline structures persisted during preparation and preservation of the elastomer at $20^{\circ} \mathrm{C}$. In addition, the characteristic diffraction peaks of BAMO micro-block crystallization disappear completely as the temperature rises to $40^{\circ} \mathrm{C}$. This fully demonstrates the thermal effect of elastomer S0 at temperatures ranging from $25^{\circ} \mathrm{C}$ to $38^{\circ} \mathrm{C}$ and the POM bright patches of this elastomer below $40{ }^{\circ} \mathrm{C}$ stem from BAMO micro-block crystallization.
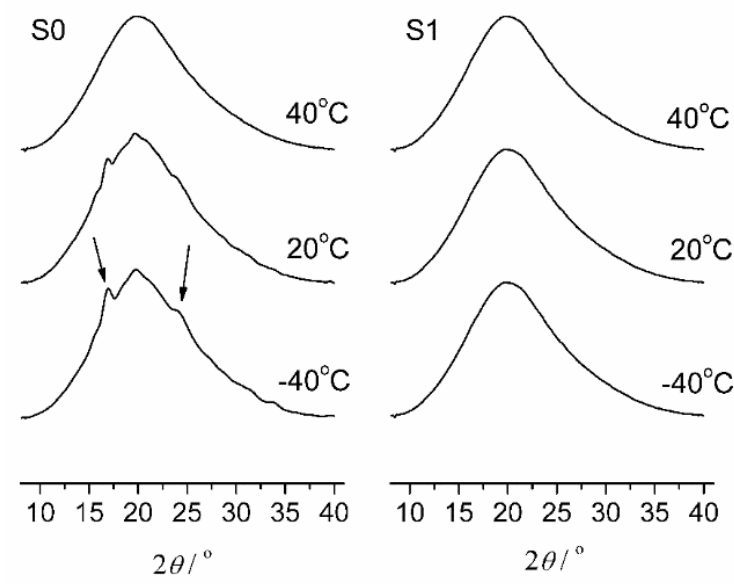

Figure 4. Wide-angle X-ray diffraction (WAXD) curves of elastomer S0 and S1 at different temperatures.

Figure 4 (Right) shows the WAXD profiles of elastomer S1, where a smooth halo peak occurs over the entire temperature scope. Due to the crystallization temperature reversibility of BAMO micro-blocks in the P(BAMO-r-THF) prepolymer [19], it can be concluded that the crosslinks within elastomer S1 exhibit decreased polymeric segment mobility and have kinetically restricted the rearrangement of polymerization segments. Semi-crystalline elastomer S0 becomes amorphous elastomer S1 after undergoing a heating-cooling cycle, and further spontaneous regeneration of the BAMO micro-block crystal grains, by just reducing the temperature, is prevented. The crystallinity of the BAMO micro-block within P(BAMO-r-THF) crosslinked elastomers is temperature irreversible, and hence, elastomer $\mathrm{S} 1$ is amorphous under static conditions.

\subsection{Mechanical Properties}

The mechanical properties obtained at different temperatures of elastomer $\mathrm{S} 0$ and $\mathrm{S} 1$ are listed in Table 2. At $20^{\circ} \mathrm{C}$, comparable break strain $\left(\varepsilon_{\mathrm{b}}\right)$ values of $315 \pm 22 \%$ (S0) and $294 \pm 6 \%$ (S1) are obtained. However, the break stress $\left(\sigma_{\mathrm{b}}\right)$ of $\mathrm{S} 0(0.46 \pm 0.01 \mathrm{MPa})$ is obviously higher than that of $\mathrm{S} 1$ $(0.32 \pm 0.02 \mathrm{MPa})$. At $-40{ }^{\circ} \mathrm{C}$, the $\varepsilon_{\mathrm{b}}$ values increase to $1085 \pm 21 \%$ for elastomer $\mathrm{S} 0$ and $1181 \pm 25 \%$ for elastomer $\mathrm{S} 1$, and the corresponding $\sigma_{\mathrm{b}}$ values increase to $8.90 \pm 0.72 \mathrm{MPa}$ and $10.23 \pm 0.44 \mathrm{MPa}$, respectively. In contrast to the mechanical-property at $20^{\circ} \mathrm{C}$, both elastomers simultaneously exhibit extremely high break strains and stresses at $-40^{\circ} \mathrm{C}$. 
Table 2. Mechanical properties of elastomers at different temperatures.

\begin{tabular}{cccccccc}
\hline Temperature & Sample & $\begin{array}{c}\text { Mechanical } \\
\text { Properties }\end{array}$ & $\mathbf{1}$ & $\mathbf{2}$ & $\mathbf{3}$ & $\mathbf{4}$ & Averages \\
\hline \multirow{2}{*}{$20^{\circ} \mathrm{C}$} & \multirow{2}{*}{$\mathrm{S} 0$} & $\varepsilon_{\mathrm{b}} / \%$ & 342 & 318 & 290 & 310 & $315 \pm 22$ \\
& $\sigma_{\mathrm{b}} / \mathrm{MPa}$ & 0.47 & 0.45 & 0.44 & 0.46 & $0.46 \pm 0.01$ \\
\cline { 2 - 7 } & \multirow{2}{*}{$\mathrm{S} 1$} & $\varepsilon_{\mathrm{b}} / \%$ & 298 & 291 & 286 & 300 & $294 \pm 6$ \\
& \multirow{2}{*}{$\mathrm{S} 0$} & $\sigma_{\mathrm{b}} / \mathrm{MPa}$ & 0.33 & 0.30 & 0.31 & 0.33 & $0.32 \pm 0.02$ \\
\hline \multirow{2}{*}{$-40^{\circ} \mathrm{C}$} & $\varepsilon_{\mathrm{b}} / \%$ & 1090 & 1054 & 1096 & 1100 & $1085 \pm 21$ \\
& \multirow{2}{*}{$\mathrm{S} 1$} & $\sigma_{\mathrm{b}} / \mathrm{MPa}$ & 8.85 & 8.03 & 9.78 & 8.94 & $8.90 \pm 0.72$ \\
\hline & $\varepsilon_{\mathrm{b}} / \%$ & 1179 & 1204 & 1192 & 1147 & $1181 \pm 25$ \\
& & $\sigma_{\mathrm{b}} / \mathrm{MPa}$ & 9.98 & 10.26 & 10.84 & 9.84 & $10.23 \pm 0.44$ \\
\hline
\end{tabular}

The typical stress-strain curves of elastomers S0 and S1 are shown in Figure 5. At $20{ }^{\circ} \mathrm{C}$, the stretching modulus of each elastomer decreases gradually with increasing strain, consistent with the state equation of elastomers [25]. Within elastomer S0, many BAMO micro-block crystal grains have formed physical crosslinks (see Figures 2 and 4), increase the apparent strand density and reduce the apparent molecular weight of the strands between the crosslinks. The elastomer stress and modulus are proportional to the density of the cross-linked elastomer strands [26]. Therefore, in Figure 5, the stress-strain curve of elastomer S0 is considerably higher than that of elastomer S1, and the break stress of $\mathrm{S} 0$ higher than that of S1. Additionally, it is noteworthy that, quite different from the stress-strain trend at $20^{\circ} \mathrm{C}$, at $-40{ }^{\circ} \mathrm{C}$ the stress-strain curves of elastomer S0 and S1 simultaneously give upturns of stress at strain of about $520 \%$ for elastomer S0, and at strain of about $290 \%$ for elastomer S1. And, their stress-strain behaviors are very similar.

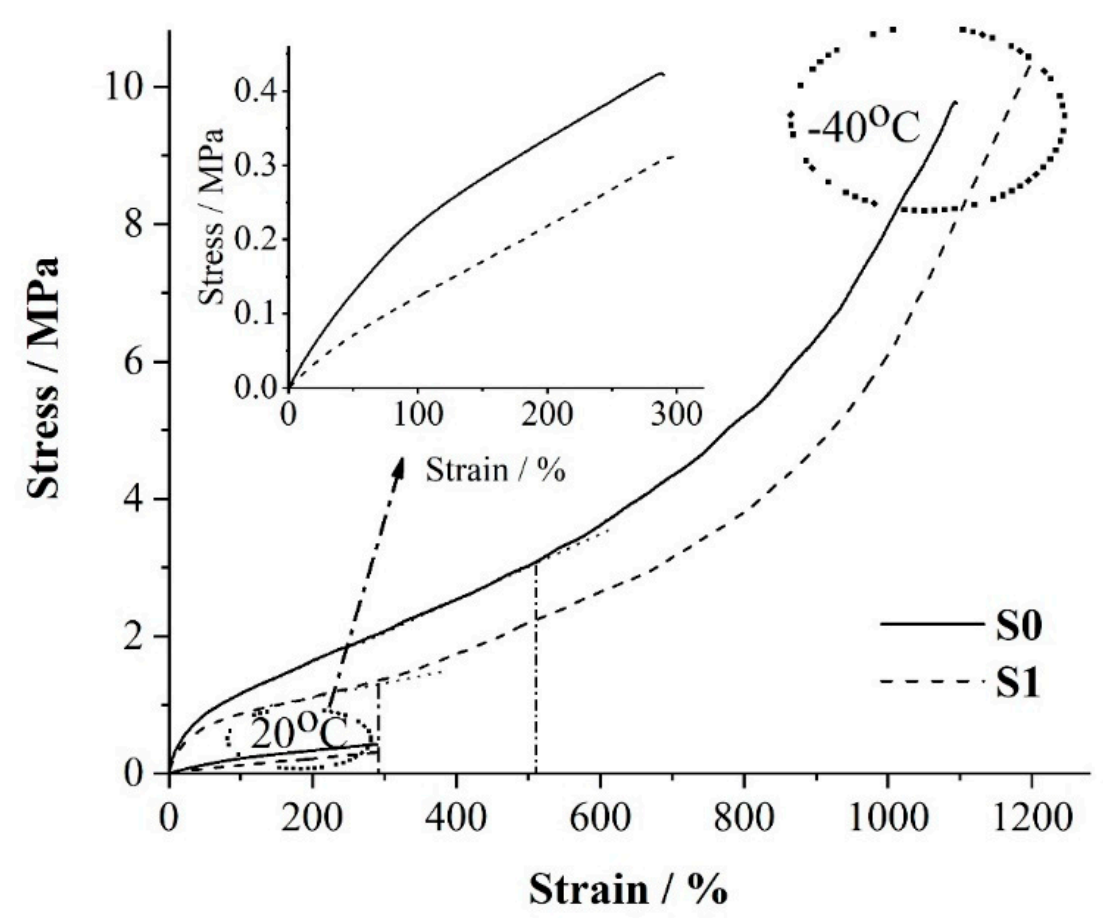

Figure 5. Stress-strain curves of elastomers.

\subsection{Aggregation Evolution}

At present, a universal in-situ tensile thermal platform for synchrotron radiation X-ray diffraction is unsuitable for measuring the low-temperature mechanical properties of polymeric elastomers. To further elaborate the mechanical response mechanism of elastomer $\mathrm{S} 0$ and $\mathrm{S} 1$ at $-40^{\circ} \mathrm{C}$, referring to 
Reference 18 as well as the POM and XRD results. Figure 6 shows the aggregation evolution process of the elastomers under different conditions.

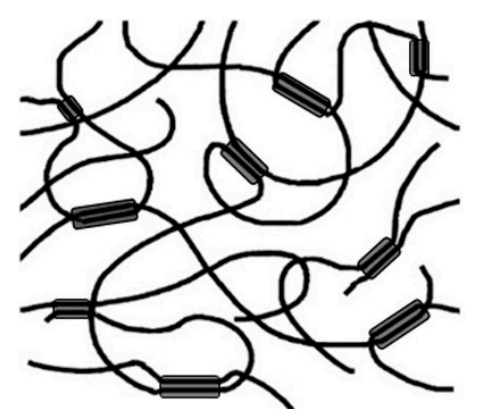

- Chemical crosslinking points

\section{Crystal grains}

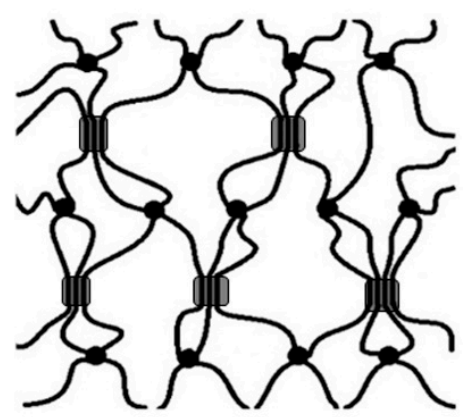

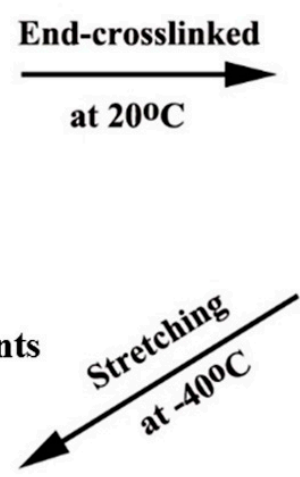

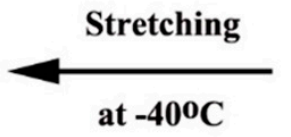

Figure 6. Schematic of the aggregation evolution for P(BAMO-r-THF) elastomer.

Due to the crystallinity of BAMO micro-blocks within prepolymer P(BAMO-r-THF) at room temperature [19], elastomer $\mathrm{S} 0$ gives a semi-crystallization aggregation as it was prepared at $20^{\circ} \mathrm{C}$. Upon stretching at $-40{ }^{\circ} \mathrm{C}$, the strands of this elastomer slide along the stretching direction and become oriented, resulting in enhanced strand segment mobility and decreased configuration entropy [27]. The low temperature contributes to further crystallization of the other BAMO micro-blocks. The consequent strain-induced crystallization of these micro-blocks increases the physical crosslinking point density among the polymeric strands. Consequently, the modulus increases with increasing strain and an upturn of stress emerges at a strain of about $520 \%$ (see Figure 5).

After undergoing a heat-treatment at $50{ }^{\circ} \mathrm{C}$, semi-crystalline elastomer S0 transforms into amorphous elastomer S1. The aggregation morphology of S1 is quite different from that of S0 under static conditions. However, the similar stress-strain behavior shown in Figure 5 implies that, upon stretching at $-40{ }^{\circ} \mathrm{C}$, the BAMO micro-blocks within amorphous elastomer $\mathrm{S} 1$ also undergo sliding and become oriented. This leads to the formation of BAMO micro-block crystal grains, with increased physical crosslinking points among the polymeric chains. Consequently, as shown in the figure, an upturn of stress at a strain of about $290 \%$ leads to an increase in the break stress. Meanwhile, strain-induced crystallization helps to elongate the segments in amorphous domains and [28], hence, the elastomers S0 and S1 simultaneously exhibit very high break strains at $-40{ }^{\circ} \mathrm{C}$. The BAMO micro-block strain-induced crystallinity yields P(BAMO-r-THF) elastomers that exhibit excellent break strain and break stress at low temperature.

\section{Conclusions}

A P(BAMO-r-THF) end cross-linked elastomer (S0) prepared at $20^{\circ} \mathrm{C}$ exhibits a semi-crystallization morphology below $40{ }^{\circ} \mathrm{C}$. After the thermal cycle, the resulting elastomer (S1) becomes completely 
amorphous. The crystallinity of the BAMO micro-blocks comprising the P(BAMO-r-THF) elastomer is temperature irreversible under static conditions.

At $20^{\circ} \mathrm{C}$, the BAMO micro-block crystal grains within elastomer $\mathrm{S} 0$ are characterized by increased crosslink density among the $\mathrm{P}$ (BAMO-r-THF) chains, and the modulus and break stress of this elastomer are higher than those of elastomer S1. At $-40^{\circ} \mathrm{C}$, due to the dual-effect of strain orientation and low temperature, BAMO micro-blocks in both elastomers undergo strain-induced crystallization, leading to a significant improvement in the mechanical properties. These findings will contribute to extending the applications of energetic P(BAMO-r-THF) binders and stimulating the design and synthesis of new energetic binders with excellent mechanical properties.

Author Contributions: Data curation, X.G. and X.L.; formal analysis, H.Z.; methodology, T.S.; writing-original draft, J.Z. All authors have read and agreed to the published version of this manuscript.

Funding: This research was funded by National Natural Science Foundation of China: 51473022.

Acknowledgments: The authors are grateful to the National Natural Science Foundation of China (Grant No. 51473022) for financial support.

Conflicts of Interest: The authors declare no conflict of interest.

\section{References}

1. Mason, B.P.; Roland, C.M. Solid Propellants. Rubber Chem. Technol. 2019, 92, 1-24. [CrossRef]

2. Sikder, A.K.; Reddy, S. Review on Energetic Thermoplastic Elastomers (ETPEs) for Military Science. Propellants Explos. Pyrotech. 2012, 38, 14-28. [CrossRef]

3. Badgujar, D.M.; Talawar, M.B.; Zarko, V.E.; Mahulikar, P.P. New directions in the area of modern energetic polymers: An overview. Combust. Explos. Shock. Waves 2017, 53, 371-387. [CrossRef]

4. Ma, M.; Kwon, Y. Reactive Energetic Plasticizers Utilizing Cu-Free Azide-Alkyne 1,3-Dipolar Cycloaddition for In-Situ Preparation of Poly(THF-co-GAP)-Based Polyurethane Energetic Binders. Polymers 2018, 10, 516. [CrossRef] [PubMed]

5. He, L.; Zhou, J.; Dai, S.; Ma, Z. Influence of Combustion Modifiers on the Cure Kinetics of Glycidyl Azide Polymer Based Propellant-Evaluated through Rheo-Kinetic Approach. Polymers 2019, 11, 637. [CrossRef] [PubMed]

6. Li, B.; Zhang, J.; Li, G.; Li, X.; Luo, Y.; Zheng, J. Influence of diisocyanate types on properties of chain-extended poly(3,3-bis(azidomethyl)oxetane). Soft Mater. 2017, 15, 205-213. [CrossRef]

7. Hardenstine, K.E.; Henderson, G.V.S.; Sperling, L.H.; Murphy, C.J.; Manser, G.E. Crystallization behavior of poly(3,3-bisethoxymethyl oxetane) and poly(3,3-bisazidomethyl oxetane). J. Polym. Sci. Polym. Phys. Ed. 1985, 23, 1597-1609. [CrossRef]

8. Miyazaki, T.; Kubota, N. Energetics of BAMO. Propellants Explos. Pyrotech. 1992, 17, 5-9. [CrossRef]

9. Nie, Y.; Gao, H.; Wu, Y.; Hu, W. Effect of comonomer sizes on the strain-induced crystal nucleation of random copolymers. Eur. Polym. J. 2016, 81, 34-42. [CrossRef]

10. Petrov, V.A.; Kuznetsova, N.V.; Muhametshin, T.I.; Gubaydullin, A.T. Structure of Urethane Copolymers of 3,3-Bis(azidomethyl)oxetane and 3-Azidomethyl-3-methyloxetane. Propellants Explos. Pyrotech. 2014, 39, 545-549. [CrossRef]

11. Sarangapani, R.; Reddy, S.T.; Sikder, A.K. Molecular dynamics simulations to calculate glass transition temperature and elastic constants of novel polyethers. J. Mol. Graph. Model. 2015, 57, 114-121. [CrossRef]

12. Zhang, C.; Li, J.; Luo, Y.; Yan, S. Synthesis and thermal decomposition of 3,3'-bis-azidomethyl oxetane-3-azidomethyl-3'-methyl oxetane random copolymer. Soft Mater. 2016, 14, 9-14. [CrossRef]

13. Kawasaki, H.; Anan, T.; Kimura, E.; Oyumi, Y. BAMO/NMMO Copolymer with Polyester Initiation. Propellants Explos. Pyrotech. 1997, 22, 87-92. [CrossRef]

14. Bednarek, M.; Kubisa, P. Cationic copolymerization of tetrahydrofuran with ethylene oxide in the presence of diols: Composition, microstructure, and properties of copolymers. J. Polym. Sci. Part A Polym. Chem. 1999, 37, 3455-3463. [CrossRef]

15. Wu, S.; Zhang, Y.; Han, J.; Xie, Z.; Xu, J.; Guo, B. Copolymerization with Polyether Segments Improves the Mechanical Properties of Biodegradable Polyesters. ACS Omega 2017, 2, 2639-2648. [CrossRef] 
16. Manser, G.E.; Guimont, J.; Ross, D.L. A new polymerization technique for preparing low molecular weight polyether glycols. In Proceedings of the JANNAF Propulsion Meeting, New Orleans, LA, USA, 26-28 May 1981; pp. 29-38.

17. Chen, T.; Li, W.; Jiang, W.; Hao, G.; Xiao, L.; Ke, X.; Liu, J.; Gao, H. Preparation and characterization of RDX/BAMO-THF energetic nanocomposites. J. Energetic Mater. 2018, 36, 424-434. [CrossRef]

18. Chen, T.; Zhang, Y.; Guo, S.F.; Zhao, L.M.; Chen, W.; Hao, G.Z.; Xiao, L.; Ke, X.; Jiang, W. Preparation and property of CL-20/BAMO-THF energetic nanocomposites. Def. Technol. 2019, 15, 306-312. [CrossRef]

19. Zhai, J.; Yang, R.; Li, J. Catalytic thermal decomposition and combustion of composite BAMO-THF propellants. Combust. Flame 2008, 154, 473-477. [CrossRef]

20. Eroğlu, M.S.; Güven, O. Characterization of network structure of poly(glycidyl azide) elastomers by swelling, solubility and mechanical measurements. Polymer 1998, 39, 1173-1176. [CrossRef]

21. Xiaoxia, J.; Yiwen, H.; Qilong, Z. Effect of thermal processing temperature on the microphase separation and mechanical properties of BAMO/THF polyurethane. J. Polym. Eng. 2017, 37, 169-176. [CrossRef]

22. Zhang, C.; Li, J.; Luo, Y. Synthesis and characterization of 3,3'-Bisazidomethyl oxetane-3azidomethyl-3'-methyl oxetane alternative block energetic thermoplastic elastomer. Propellants Explos. Pyrotech. 2012, 37, 235-240. [CrossRef]

23. Zhai, J.; Jia, H.; Guo, X.; Guo, A. Sequence Structure, Morphology and Viscosity Behavior of 3,3-bis(azidomethyl) Oxetane-tetrahydrofuran Random Copolyether. Propellants Explos. Pyrotech. 2017, 42, 643-648. [CrossRef]

24. Zhou, Y.; Xin-Ping, L.; Qing-Xuan, Z. Simulation study on the liquid-crystalline ordering and fluidity of energetic diblock copolymers based on poly[3,3-bis(azidomethyl) oxetane]. J. Appl. Polym. Sci. 2013, 129, 2772-2778.

25. Mark, J.E.; Erman, B.; Eirich, F.R. The Science and Technology of Rubber, 3rd ed.; Elsevier academic press: Burlington, NJ, USA, 2005; pp. 1-27.

26. Mark, J.E. Rubber elasticity. J. Chem. Educ. 1981, 58, 898. [CrossRef]

27. Fernandez, J.O.; Swallowe, G.M. Crystallization of PET with strain, strain rate and temperature. J. Mater. Sci. 2000, 35, 4405-4414. [CrossRef]

28. Mark, J.E. The effect of strain-induced crystallization on the ultimate properties of an elastomeric polymer network. Polym. Eng. Sci. 1979, 19, 409-413. [CrossRef]

Publisher's Note: MDPI stays neutral with regard to jurisdictional claims in published maps and institutional affiliations.

(C) 2020 by the authors. Licensee MDPI, Basel, Switzerland. This article is an open access article distributed under the terms and conditions of the Creative Commons Attribution (CC BY) license (http://creativecommons.org/licenses/by/4.0/). 